Article

\title{
Streptoglycerides E-H, Unsaturated Polyketides from the Marine-Derived Bacterium Streptomyces specialis and Their Anti-Inflammatory Activity
}

\author{
Hee Jae Shin ${ }^{1,2, *(D)}$, Chang-Su Heo ${ }^{1,2}$, Cao Van Anh ${ }^{1,2}$, Yeo Dae Yoon ${ }^{3}$ and Jong Soon Kang ${ }^{3}$ \\ 1 Marine Natural Products Chemistry Laboratory, Korea Institute of Ocean Science and Technology, \\ 385 Haeyang-ro, Yeongdo-gu, Busan 49111, Korea; science30@kiost.ac.kr (C.-S.H.); \\ caovananh@kiost.ac.kr (C.V.A.) \\ 2 Department of Marine Biotechnology, University of Science and Technology (UST), 217 Gajungro, Yuseong-gu, \\ Daejeon 34113, Korea \\ 3 Laboratory Animal Resource Center, Korea Research Institute of Bioscience and Biotechnology, \\ 30 Yeongudanjiro, Cheongju 28116, Korea; yunyd76@kribb.re.kr (Y.D.Y.); kanjon@kribb.re.kr (J.S.K.) \\ * Correspondence: shinhj@kiost.ac.kr; Tel.: +82-51-664-3341; Fax: +82-51-664-3340
}

Citation: Shin, H.J.; Heo, C.-S.; Anh, C.V.; Yoon, Y.D.; Kang, J.S.

Streptoglycerides E-H, Unsaturated Polyketides from the Marine-Derived Bacterium Streptomyces specialis and Their Anti-Inflammatory Activity. Mar. Drugs 2022, 20, 44. https:// doi.org/10.3390/md20010044

Academic Editor: Bill J. Baker

Received: 8 December 2021

Accepted: 23 December 2021

Published: 1 January 2022

Publisher's Note: MDPI stays neutral with regard to jurisdictional claims in published maps and institutional affiliations.

Copyright: (C) 2022 by the authors. Licensee MDPI, Basel, Switzerland. This article is an open access article distributed under the terms and conditions of the Creative Commons Attribution (CC BY) license (https:// creativecommons.org/licenses/by/ $4.0 /)$.

\begin{abstract}
Four new streptoglycerides E-H (1-4), with a rare 6/5/5/-membered ring system, were isolated from a marine-derived actinomycete Streptomyces specialis. The structures of 1-4 were elucidated by detailed analysis of HRESIMS, 1D and 2D NMR data and ECD spectra as well as comparison of their spectroscopic data with those reported in literature. Compounds 1-4 showed significant antiinflammatory activity by inhibiting lipopolysaccharide (LPS)-induced nitric oxide (NO) production in Raw 264.7 cells with $\mathrm{IC}_{50}$ values ranging from 3.5 to $10.9 \mu \mathrm{M}$. Especially, 2 suppressed mRNA expression levels of iNOS and IL-6 without cytotoxicity.
\end{abstract}

Keywords: marine-derived bacterium; Streptomyces specialis; streptoglycerides; anti-inflammatory

\section{Introduction}

Inflammation is a normal defense mechanism that occurs to cope with tissue damage and microbial infection [1]. When tissues are exposed to LPS, NO and cytokines such as interleukins (IL- 6 and IL-1 $\beta$ ), and tumor necrosis factor- $\alpha$ (TNF- $\alpha$ ) are produced naturally $[2,3]$. However, the uncontrolled cytokine overproduction promotes a variety of diseases [4]. NO and interleukins play a central role in the pathogenesis of inflammation owing to overproduction under abnormal physiological conditions $[5,6]$. Therefore, $\mathrm{NO}$ and interleukins are considered as a critical indicator for developing drugs for inflammatory diseases $[7,8]$.

Up to now, there have been many reports on marine natural products with antiinflammatory activity [9-11]. Marine organisms inhabiting extreme environments have adopted unique survival strategies for growing and reproducing under hostile conditions, biosynthesizing molecules valuable for pharmaceutical applications [12,13]. Marine Streptomyces are an especially attractive source for exploring marine natural products as they produce various kinds of secondary metabolites with potent biological activities [14,15].

Recently, we reported streptoglycerides A-D with a quite rare $6 / 5 / 5$ heterocyclic scaffold and anti-inflammatory activity isolated from a strain of marine-derived Streptomyces sp. [16]. During our ongoing investigation of secondary metabolites from marine microorganisms, we encountered another strain, designated as Streptomyces specialis 208DD-067, isolated from a sediment sample collected off Dokdo, South Korea, which produced new derivatives of streptoglycerides (1-4). Herein, we report the isolation, structure elucidation and anti-inflammatory activity of streptoglycerides E-H (1-4) (Figure 1). 

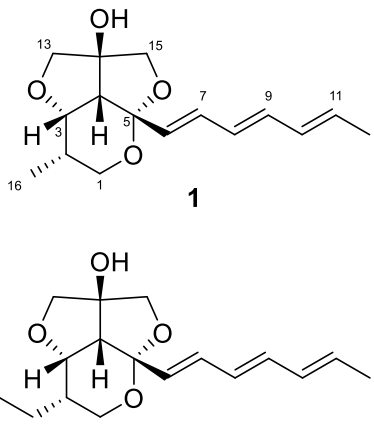

3

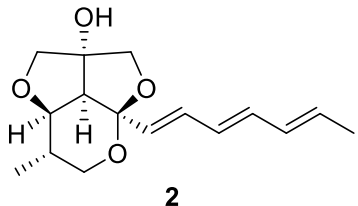

2

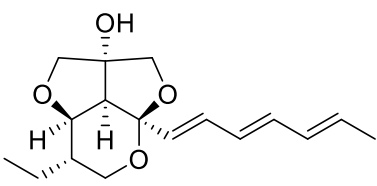

4

Figure 1. Structures of streptoglycerides E-H (1-4).

\section{Results and Discussion}

\subsection{Structural Elucidation}

Compound $\mathbf{1}$ was isolated as a white powder. The molecular formula of $\mathbf{1}$ was determined to be $\mathrm{C}_{16} \mathrm{H}_{22} \mathrm{O}_{4}$ by combined analysis of HRESIMS $\left(\mathrm{m} / z\right.$ 301.1417 [M+Na] ${ }^{+}$, calcd. for $\left.\mathrm{C}_{16} \mathrm{H}_{22} \mathrm{O}_{4} \mathrm{Na} 301.1416\right)$ and NMR data. The ${ }^{1} \mathrm{H}$ NMR spectra of 1 displayed signals of two methyl groups at $\delta_{\mathrm{H}} 0.94\left(\mathrm{~d}, J=7.0, \mathrm{H}_{3}-16\right)$ and $1.76\left(\mathrm{~d}, J=7.0, \mathrm{H}_{3}-12\right)$; a methine at $\delta_{\mathrm{H}} 2.41(\mathrm{~d}, J=7.0, \mathrm{H}-4)$; six oxygenated methylenes at $\delta_{\mathrm{H}} 3.36-4.00$; an oxygenated methine at $\delta_{\mathrm{H}} 4.11(\mathrm{dd}, J=7.0,3.1, \mathrm{H}-3)$ and six olefinic protons at $\delta_{\mathrm{H}} 5.66-6.40$ (Table 1). The ${ }^{13} \mathrm{C}$ NMR and HSQC spectra of 1 exhibited the presence of two methyl carbons at $\delta_{\mathrm{C}} 13.0$ and 18.4; three oxygenated methylene carbons at $\delta_{\mathrm{C}} 62.3,78.4$ and 79.7; an oxygenated methine carbon at $\delta_{\mathrm{C}} 80.0$; eight methine carbons at $\delta_{\mathrm{C}} 32.1,54.3,130.3$, $131.5,131.8,132.9,136.0$ and 133.6; and two nonprotonated carbons at $\delta_{\mathrm{C}} 87.4$ and 106.1 (Table 1).

The planar structure of 1 was elucidated by detailed analysis of ${ }^{1} \mathrm{H}-{ }^{1} \mathrm{H}$ COSY and HMBC data. The structure of ring A was determined as a 2,3,4-substituted-5-methyltetrahydropyran by the continuous COSY correlations from $\mathrm{H}-1 \mathrm{a}, \mathrm{b}$ to $\mathrm{H}-4$ through $\mathrm{H}-2$, $\mathrm{H}-3$, and $\mathrm{H}_{3}-16$ and the HMBC correlations from $\mathrm{H}-1 \mathrm{a}, \mathrm{b}$ to $\mathrm{C}-5$ (Figure 2). The HMBC correlations from $\mathrm{H}-13 \mathrm{a}, \mathrm{b}$ to $\mathrm{C}-14$ and $\mathrm{C}-15$; and $\mathrm{H}-15 \mathrm{a}, \mathrm{b}$ to $\mathrm{C}-13$ and $\mathrm{C}-14$ and their chemical shifts of $\delta_{\mathrm{C}} 79.7$ (C-13), 87.4 (C-14), and 78.4 (C-15) identified a partial structure corresponding to a 2-C-substituted glycerol moiety. The HMBC correlations from H-13a,b to $\mathrm{C}-3$ and $\mathrm{C}-4$ and from $\mathrm{H}-15 \mathrm{a}, \mathrm{b}$ to $\mathrm{C}-4$ and $\mathrm{C}-5$ confirmed the connection of the glycerol moiety to the ring $A$ via ether linkages of $C-3 / C-13$ and $C-5 / C 15$ and the linkage between C-4 and C-14 was also determined by the HMBC correlations from H-13a,b to C-4 and C-14 and $\mathrm{H}-15 \mathrm{a}, \mathrm{b}$ to $\mathrm{C}-4$ and $\mathrm{C}-14$. The presence of a triene side chain was determined by the continuous COSY correlations from $\mathrm{H}-6$ to $\mathrm{H}_{3}-12$ and the connection of the side chain to the ring $\mathrm{A}$ at C-5 was confirmed by the HMBC correlations from H-6 to C-4 and C-5 and from $\mathrm{H}-7$ to $\mathrm{C}-5$. Thus, the planar structure of $\mathbf{1}$ was determined as 2-methylstreptoglyceride B which is closely related to streptoglyceride B, recently isolated from Streptomyces sp. [16].
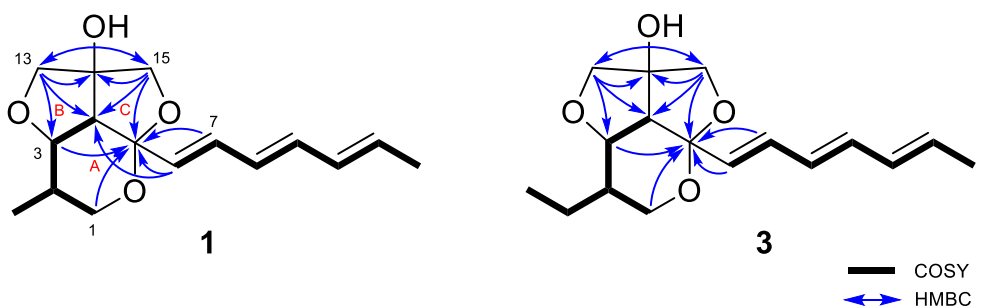

Figure 2. Key ${ }^{1} \mathrm{H}_{-}{ }^{1} \mathrm{H}$ COSY and HMBC correlations for streptoglycerides E (1) and G (3). 
Table 1. ${ }^{1} \mathrm{H}$ and ${ }^{13} \mathrm{C}$ NMR data for $\mathbf{1}-\mathbf{4}$ at $600 \mathrm{MHz}$ and $150 \mathrm{MHz}$ in $\mathrm{CD}_{3} \mathrm{OD}(\delta$ in ppm, $J$ in $\mathrm{Hz})$, respectively.

\begin{tabular}{|c|c|c|c|c|c|c|c|c|}
\hline \multirow{2}{*}{ No } & \multicolumn{2}{|c|}{1} & \multicolumn{2}{|c|}{2} & \multicolumn{2}{|c|}{3} & \multicolumn{2}{|c|}{4} \\
\hline & $\delta_{\mathrm{H}}$, mult $(J$ in $\mathrm{Hz})$ & $\delta_{\mathrm{C}}$ & $\delta_{\mathrm{H}}$, mult $(J$ in $\mathrm{Hz})$ & $\delta_{\mathrm{C}}$ & $\delta_{\mathrm{H}}$, mult $(J$ in $\mathrm{Hz})$ & $\delta_{\mathrm{C}}$ & $\delta_{\mathrm{H}}$, mult $(J$ in $\mathrm{Hz})$ & $\delta_{\mathrm{C}}$ \\
\hline $1 \mathrm{a}$ & $3.36, \mathrm{dd}(10.9,4.3)$ & 62.3 & $3.35, \mathrm{dd}(11.2,1.4)$ & 61.7 & $3.44, \mathrm{dd}(10.9,4.3)$ & 61.3 & 3.49, d-like & 59.3 \\
\hline $1 b$ & 3.74 , overlapped & & $4.13, \mathrm{dd}(11.2,2.1)$ & & 3.75 , overlapped & & 4.08, overlapped & \\
\hline 2 & $1.92, \mathrm{~m}$ & 32.1 & $1.80, \mathrm{~m}$ & 31.1 & $1.69, \mathrm{~m}$ & 38.8 & $1.52, \mathrm{~m}$ & 38.2 \\
\hline 3 & $4.11, \mathrm{dd}(7.0,3.1)$ & 80.0 & 3.99, overlapped & 81.4 & $4.21, \mathrm{dd}(7.1,3.1)$ & 78.2 & 4.07 , overlapped & 80.4 \\
\hline 4 & $2.41, \mathrm{~d}(7.0)$ & 54.3 & $2.40, \mathrm{~d}(7.2)$ & 51.5 & $2.41, \mathrm{~d}(7.1)$ & 54.3 & $2.38, \mathrm{~d}(7.3)$ & 51.8 \\
\hline 5 & & 106.1 & & 106.2 & & 106.4 & & 106.2 \\
\hline 6 & $5.66, \mathrm{~d}(15.3)$ & 133.6 & $5.68, \mathrm{~d}(15.3)$ & 133.7 & $5.67, \mathrm{~d}(15.4)$ & 133.6 & $5.67, \mathrm{~d}(15.3)$ & 133.7 \\
\hline 8 & 6.11 , overlapped & 130.3 & 6.12 , overlapped & 130.2 & 6.12 , overlapped & 130.3 & 6.12 , overlapped & 130.2 \\
\hline 9 & 6.26, dd $(14.9,10.6)$ & 136.0 & 6.27, dd $(14.9,10.5)$ & 136.1 & 6.26, dd $(14.9,10.6)$ & 136.0 & 6.26, dd $(14.9,10.6)$ & 136.1 \\
\hline 10 & 6.10 , overlapped & 132.9 & 6.11 , overlapped & 132.9 & 6.11 , overlapped & 132.9 & 6.11 , overlapped & 132.9 \\
\hline 11 & $5.75, \mathrm{~m}$ & 131.5 & $5.76, \mathrm{~m}$ & 131.5 & $5.76, \mathrm{~m}$ & 131.5 & $5.76, \mathrm{~m}$ & 131.5 \\
\hline 12 & $1.76, \mathrm{~d}(7.0)$ & 18.4 & $1.76, \mathrm{~d}(6.1)$ & 18.4 & $1.77, \mathrm{~d}(6.6)$ & 18.4 & $1.76, \mathrm{~d}(7.0)$ & 18.4 \\
\hline $13 a$ & 3.62, overlapped & 79.7 & $3.64, \mathrm{~d}(8.8)$ & 79.3 & $3.62, \mathrm{~d}(8.9)$ & 79.7 & $3.64, \mathrm{~d}(8.9)$ & 79.2 \\
\hline $13 b$ & 4.02, overlapped & & 4.01, overlapped & & 4.01 , overlapped & & 4.03, overlapped & \\
\hline 14 & & 87.4 & & 88.4 & & 88.0 & & 88.5 \\
\hline $15 a$ & 3.76 , overlapped & 78.4 & $3.77, \mathrm{~d}(9.3)$ & 78.2 & 3.77 , overlapped & 78.4 & $3.78, \mathrm{~d}(9.3)$ & 78.3 \\
\hline $16 a$ & $0.94, \mathrm{~d}(7.0)$ & 13.0 & $1.07, \mathrm{~d}(7.3)$ & 15.2 & $1.31, \mathrm{~m}$ & 21.5 & $1.42, \mathrm{~m}$ & 22.9 \\
\hline $16 \mathrm{~b}$ & & & & & $1.40, \mathrm{~m}$ & & $1.48, \mathrm{~m}$ & \\
\hline 17 & & & & & $0.97, \mathrm{t}(7.4)$ & 11.5 & $1.02, \mathrm{t}(7.3)$ & 12.1 \\
\hline
\end{tabular}


The relative configuration of $\mathbf{1}$ was determined by NOESY correlations and coupling constant analysis (Figure 3). The geometries of double bonds in the triene chain were deduced as $E$-configuration on the basis of their large coupling constants $(J \geq 14 \mathrm{~Hz}$, Table 1$)$. The NOESY correlations from $\mathrm{H}-4$ to $\mathrm{H}-2, \mathrm{H}-3, \mathrm{H}-6$, and $\mathrm{H}-7$ suggested that these protons had a cofacial relationship. The coupling constant $(7.0 \mathrm{~Hz})$ for $\mathrm{H}-3$ and $\mathrm{H}-4$ also indicated these two protons are located as a syn-arrangement.
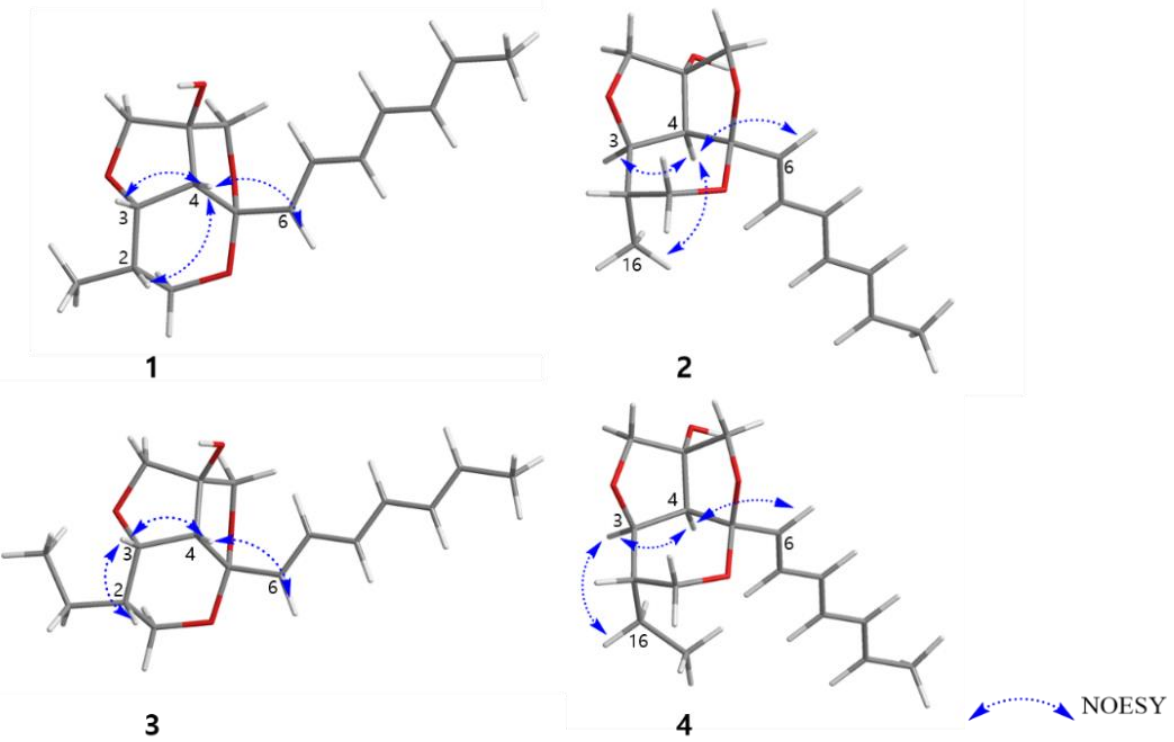

Figure 3. Key NOESY correlations of 1-4.

Furthermore, the fact that the furofuran ring system (rings B and C) is a rigid structure and always has a cis-fused relationship, on the basis of general stereochemical considerations, and the lack of NOE correlations from $\mathrm{H}-6$ to $\mathrm{H}-13 \mathrm{~b}$ and $\mathrm{H}-15 \mathrm{~b}$ allowed us to determine the relative configuration of $\mathrm{C}-14$ (OH-14 and $\mathrm{H}-4$ had a cis-relationship) $[17,18]$. Therefore, the relative configuration of C-2, C-3, C-4, C-5 was determined as $2 S^{*}, 3 S^{*}, 4 R^{*}$, $5 S^{*}$ as depicted in Figure 3. To further confirm this fact, the 3D models and conformational analysis of two possible relative configurations of $\mathbf{1}\left(2 S^{*}, 3 S^{*}, 4 R^{*}, 5 S^{*}, 14 S^{*}\right)$ and $\mathbf{1}^{\prime}\left(2 S^{*}\right.$, $3 S^{*}, 4 R^{*}, 5 S^{*}, 14 R^{*}$ ) were built by Conflex program and their ${ }^{1} \mathrm{H}$ and ${ }^{13} \mathrm{C}$ chemical shifts were calculated by Gaussian software. Using both ${ }^{1} \mathrm{H}$ and ${ }^{13} \mathrm{C}$ NMR chemical shifts in the DP4+ probability output resulted in a 100\% preference for the $\mathbf{1}$ diastereomer over the $\mathbf{1}^{\prime}$ diastereomer (Figure 4, Figure S33 in the supplementary). This result also supported the fact that $\mathrm{H}-4$ and $\mathrm{OH}-14$ are cofacial. Thus, there were only two possible absolute configurations of the $6 / 5 / 5$ tricyclic ring system for $\mathbf{1}$ as $\mathbf{1 A}(2 S, 3 S, 4 R, 5 S, 14 S)$ or $\mathbf{1 B}(2 R$, $3 R, 4 S, 5 R, 14 R)$
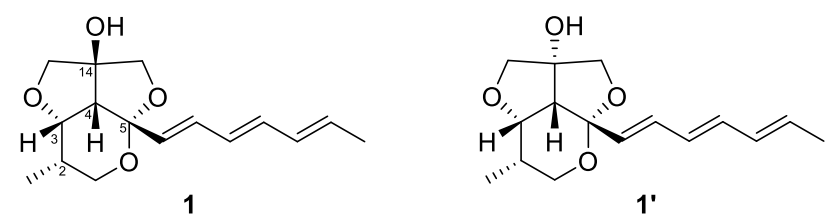

Figure 4. Structures of $\mathbf{1}$ and $\mathbf{1}^{\prime}$.

The absolute configuration of $\mathbf{1}$ was determined by ECD spectrum calculations. The theoretical ECD spectra of $\mathbf{1 A}(2 S, 3 S, 4 R, 5 S, 14 S)$ and its enantiomer $\mathbf{1 B}(2 R, 3 R$, $4 S, 5 R, 14 R)$ were generated by the Gaussian 16 program. The experimental ECD spectrum of 1 showed a good agreement with the calculated ECD spectrum of 1A (Figure 5). Therefore, the absolute configuration of 1 was determined as $2 S, 3 S, 4 R, 5 S$, 14S, which 
was same to other natural products with the 6/5/5 tricyclic ring skeleton (diocollettine $\mathrm{A}$, streptoglycerides A-D, and bafilomycins P-Q) $[16,17,19]$. Thus, $\mathbf{1}$ was determined as a new derivative of streptoglyceride $\mathrm{B}$ and named streptoglyceride $\mathrm{E}$.

(a)

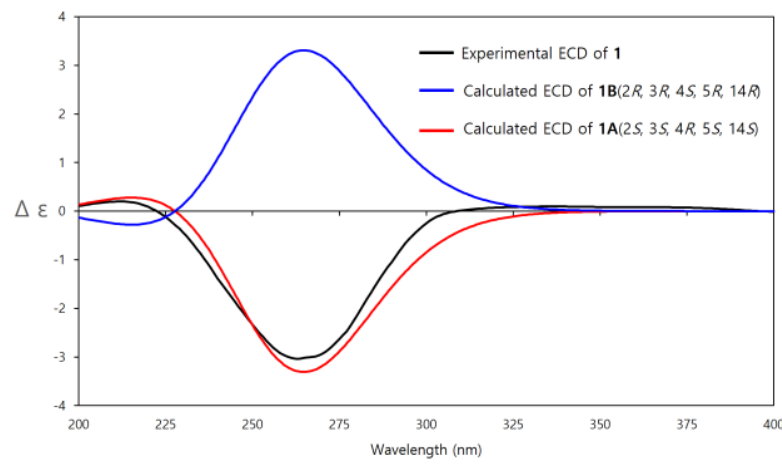

(b)

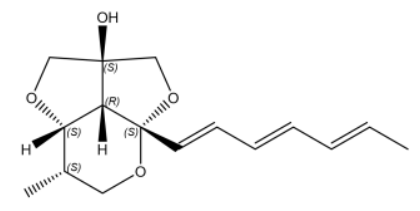

$1 \mathrm{~A}(2 \mathrm{~S}, 3 \mathrm{~S}, 4 \mathrm{R}, 5 \mathrm{~S}, 14 \mathrm{~S})$

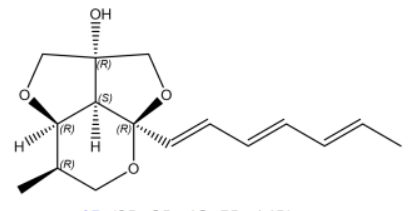

$1 B(2 R, 3 R, 4 S, 5 R, 14 R)$

Figure 5. (a) Experimental and calculated ECD spectra of 1A and 1B. (b) Absolute configurations of 1A $(2 S, 3 S, 4 R, 5 S, 14 S)$ and its enantiomer $\mathbf{1 B}(2 R, 3 R, 4 S, 5 R, 14 R)$.

Compound 2 was also isolated as a white powder. The molecular formula of 2 was determined to be the same as that of $1, \mathrm{C}_{16} \mathrm{H}_{22} \mathrm{O}_{4}$ by HRESIMS data $(\mathrm{m} / z \text { 301.1417 [M+Na] }]^{+}$, calcd. for $\mathrm{C}_{16} \mathrm{H}_{22} \mathrm{O}_{4} \mathrm{Na}, 301.1416$ ). The 1D and 2D NMR data of 2 were similar but not identical to those of $\mathbf{1}$, and by detailed analysis of HMBC and COSY data, the planar structure of $\mathbf{2}$ was determined to be the same as $\mathbf{1}$, suggesting that $\mathbf{2}$ is a diastereomer of $\mathbf{1}$. Additionally, the optical rotation values of $2\left\{[\alpha]_{\mathrm{D}}^{25}+10.0(c 0.1, \mathrm{MeOH})\right\}$ and $\mathbf{1}\left\{[\alpha]_{\mathrm{D}}^{25}-20.0(c 0.1, \mathrm{MeOH})\right\}$ also supported their stereoisomeric relationship.

The relative configuration of 2 was also determined by analysis of NOESY data and coupling constants. The strong NOESY correlations between $\mathrm{H}-4$ and H-3, H-6 and $\mathrm{H}_{3}-16$ indicated that these protons were located on the same face of the molecule. The significant difference between 2 and 1 was the methyl group $\left(\mathrm{H}_{3}-16\right)$ located on the same face with $\mathrm{H}-4$ in 2, while $\mathrm{H}-4$ and $\mathrm{H}_{3}-16$ had a trans-relationship in 1. Furthermore, the fact that $\mathrm{H}-4$ and $\mathrm{OH}-14$ had a co-facial relationship was determined by a similar procedure to that of $\mathbf{1}$. Therefore, the relative configuration of 2 was determined as $2 S^{*}, 3 R^{*}, 4 S^{*}, 5 R^{*}, 14 R^{*}(\mathbf{2 A})$ (Figure 3).

The absolute configuration of 2 was determined by comparison of its experimental ECD spectrum with calculated ECD spectra of $\mathbf{2 A}(2 S, 3 R, 4 S, 5 R, 14 R)$ and its enantiomer 2B $(2 R, 3 S, 4 R, 5 S, 14 S)$. The experimental ECD spectrum of 2 matched well with the calculated ECD spectrum of 2A (Figure 6). Therefore, the absolute configuration of $\mathbf{2}$ was determined as $2 S, 3 R, 4 S, 5 R, 14 R$. Thus, 2 was a new diastereomer of $\mathbf{1}$ and named streptoglyceride $\mathrm{F}$.

Compound $\mathbf{3}$ was isolated as a white powder. The molecular formula of $\mathbf{3}$ was determined to be $\mathrm{C}_{17} \mathrm{H}_{24} \mathrm{O}_{4}$ by HR-ESIMS data $\left(\mathrm{m} / \mathrm{z} 315.1570[\mathrm{M}+\mathrm{Na}]^{+}\right.$, calcd. for $\mathrm{C}_{17} \mathrm{H}_{24} \mathrm{O}_{4} \mathrm{Na}$ 315.1572), one methylene group $\left(-\mathrm{CH}_{2}-\right)$ more than that of $\mathbf{1}$. The ${ }^{1} \mathrm{H}$ and ${ }^{13} \mathrm{C} \mathrm{NMR}$ data of 3 were almost identical to that of $\mathbf{1}$, except for the presence of one more methylene group at $\delta_{\mathrm{C}} 21.5(\mathrm{C}-16)$ and $\delta_{\mathrm{H}} 1.31(\mathrm{H}-16 \mathrm{a})$ and $1.40(\mathrm{H}-16 \mathrm{~b})$. Furthermore, the continuous COSY correlations from $\mathrm{H}_{3}-17\left(\delta_{\mathrm{H}} 0.97\right)$ to $\mathrm{H}-2\left(\delta_{\mathrm{H}} 1.69\right)$ via $\mathrm{H}-16 \mathrm{a}$,b suggested that an ethyl group was substituted at C-2 in $\mathbf{3}$ instead of a methyl substitution in $\mathbf{1}$. Thus, the planar structure of 3 was determined as 2-ethylstreptoglyceride B (Figure 2). 
(a)

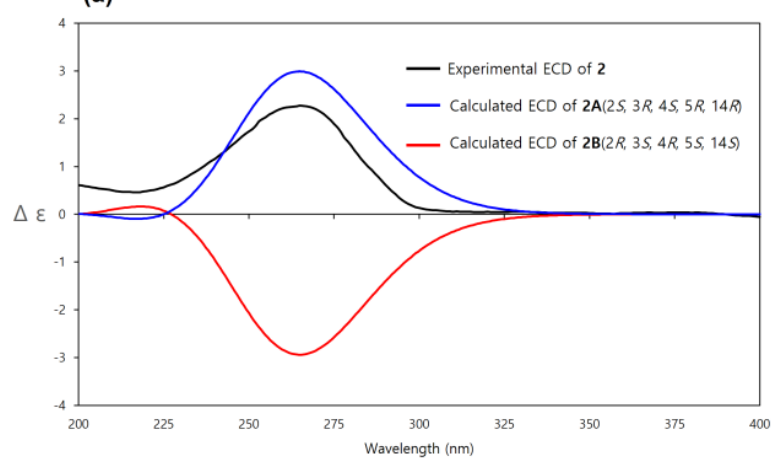

(b)

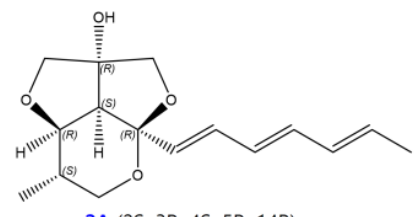

$2 A(2 S, 3 R, 4 S, 5 R, 14 R)$

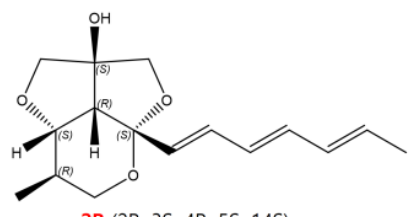

Figure 6. (a) Experimental and calculated ECD spectra of 2A and 2B. (b) Absolute configurations of 2A $(2 S, 3 R, 4 S, 5 R, 14 R)$ and its enantiomer $\mathbf{2 B}(2 R, 3 S, 4 R, 5 S, 14 S)$.

The relative configuration of 3 was determined to be the same as 1 by the same aforementioned procedure for $1,\left(2 S^{*}, 3 S^{*}, 4 R^{*}, 5 S^{*}, 14 S^{*},(3 \mathrm{~A})\right.$ ) (Figure 3 ), and the experimental ECD spectrum of $\mathbf{3}$ was compared to the calculated ECD spectra of $\mathbf{3 A}$ and its enantiomer 3B. The experimental ECD spectrum of $\mathbf{3}$ was well-matched to the calculated ECD spectrum of $3 \mathrm{~A}$ (Figure 7). Therefore, the absolute configuration of 3 was determined as $2 S, 3 S, 4 R$, $5 S, 14 S$. Thus, the structure of 3 was determined as a new derivative of streptoglyceride $B$ and named streptoglyceride G.

(a)

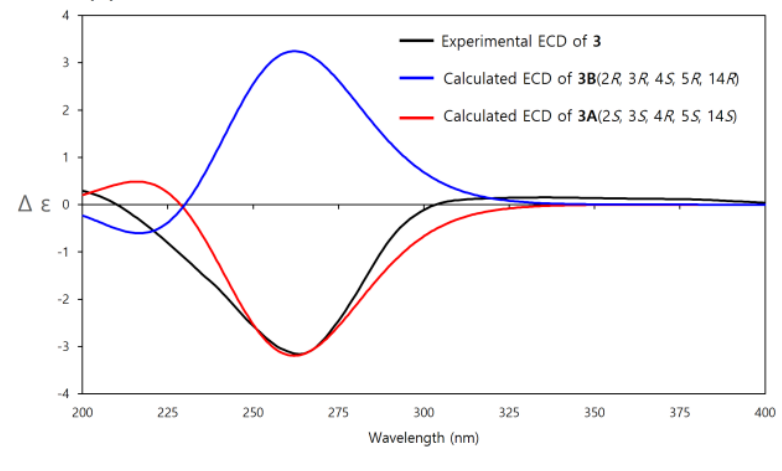

(b)
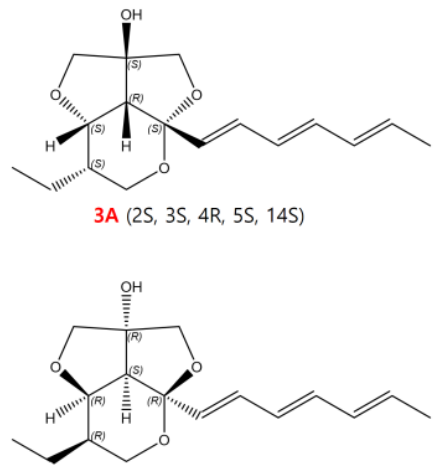

3B $(2 R, 3 R, 4 S, 5 R, 14 R)$

Figure 7. (a) Experimental and calculated ECD spectra of 3A and 3B. (b) Absolute configurations of 3A $(2 S, 3 S, 4 R, 5 S, 14 S)$ and its enantiomer $3 \mathbf{B}(2 R, 3 R, 4 S, 5 R, 14 R)$.

Compound 4 was isolated as a white powder. The molecular formula of 4 was determined to be the same as that of $3, \mathrm{C}_{17} \mathrm{H}_{24} \mathrm{O}_{4}$ by HR-ESIMS data $\left(\mathrm{m} / z 315.1573[\mathrm{M}+\mathrm{Na}]^{+}\right.$, calcd. for $\mathrm{C}_{17} \mathrm{H}_{24} \mathrm{O}_{4} \mathrm{Na}, 315.1572$ ). The 1D and 2D NMR data of 4 were also almost identical to those of 3 and by detailed analysis of HMBC and COSY data, the planar structure of 4 was determined to be the same as 3, (2-ethylstreptoglyceride B). However, the optical rotation values of $4\left\{[\alpha]_{\mathrm{D}}^{25}+30.0(c 0.1, \mathrm{MeOH})\right\}$ and $\mathbf{3}\left\{[\alpha]_{\mathrm{D}}^{25}-40.0(c 0.1, \mathrm{MeOH})\right\}$ suggested that they had a stereoisomeric relationship.

The relative configuration of 4 was determined to be the same as 2 by the same abovementioned procedure for $2\left(2 S^{*}, 3 R^{*}, 4 S^{*}, 5 R^{*}, 14 R^{*},(4 \mathrm{~A})\right)$ and the experimental ECD spectrum of 4 was compared to the calculated ECD spectra of $4 \mathbf{A}(2 S, 3 R, 4 S, 5 R, 14 R)$ and its enantiomer $4 \mathbf{B}(2 \mathrm{R}, 3 S, 4 R, 5 S, 14 S)$. The experimental ECD spectrum of 4 was well matched to the calculated ECD spectrum of $4 \mathrm{~A}$ (Figure 8). Therefore, the absolute configuration of 4 was determined as $2 S, 3 R, 4 S, 5 R, 14 R$. Thus, 4 was determined as a new diastereomer of 3 and named streptoglyceride $\mathrm{H}$. 
(a)

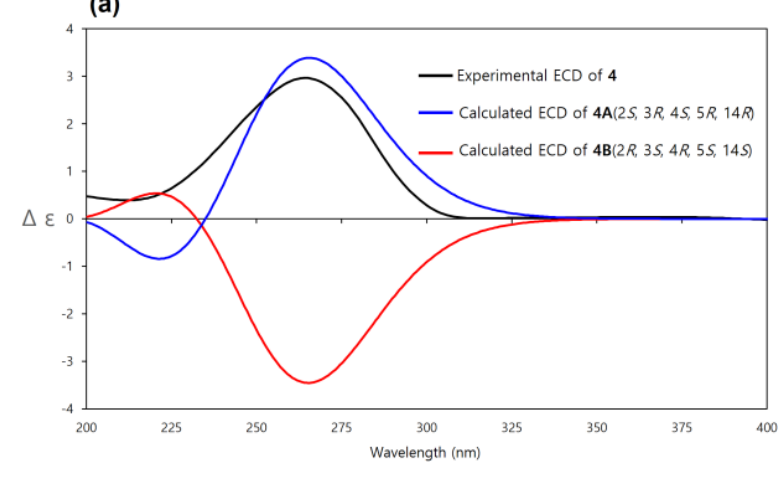

(b)
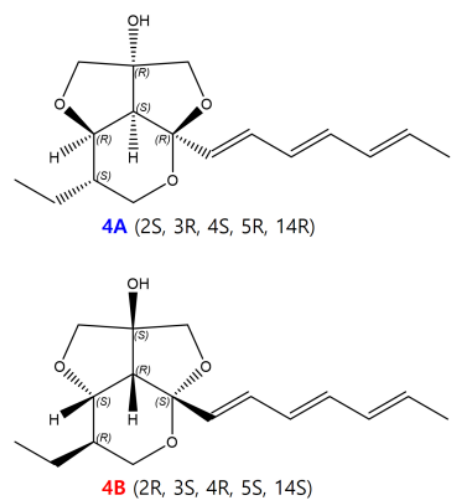

Figure 8. (a) Experimental and calculated ECD spectra of $4 \mathrm{~A}$ and $4 \mathrm{~B}$. (b) Absolute configurations of $4 \mathbf{A}(2 S, 3 R, 4 S, 5 R, 14 R)$ and its enantiomer $4 \mathbf{B}(2 R, 3 S, 4 R, 5 S, 14 S)$.

The biosynthetic pathway of streptoglyceride A-D was previously proposed [20]. Similarly, we propose a plausible biosynthetic pathway of 1-4 (Scheme 1). The polyketide synthase (PKS) clusters would lead to the formation of a hexaketide intermediate $\mathbf{i}$ as a starting compound. The intermediate $\mathbf{i}$ could be converted to ii to form an intermediate with a rare $5 / 5$ furo[3,4-c]furan ring. Afterward, cyclization of ii affords intermediate iii, which could be further converted into streptoglycerides E-H possessing a rare $6 / 5 / 5$ ring system.

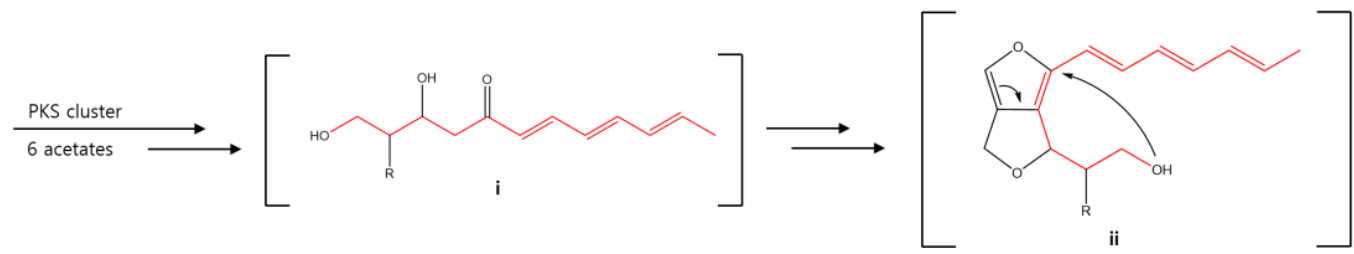

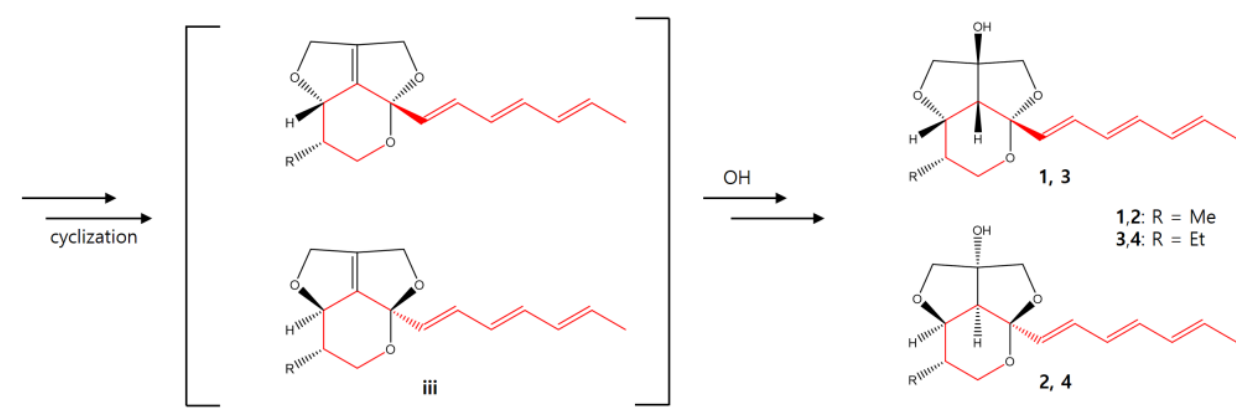

Scheme 1. Plausible biosynthesis pathway of 1-4.

\subsection{Bioactivities}

Compounds 1-4 were screened for their effects on the production of NO in LPSstimulated RAW 264.7 mouse macrophage cell line. All four compounds showed moderate inhibitory effects with $\mathrm{IC}_{50}$ values ranging from 3.5 to $10.9 \mu \mathrm{M}$ (Table 2). The test was performed four times to confirm the reproducibility and statistical analyses were conducted using a t-test. 
Table 2. Inhibitory effects of 1-4 on LPS-induced NO production in RAW 264.7 cells.

\begin{tabular}{cc}
\hline Compounds & IC $_{\mathbf{5 0}}, \boldsymbol{\mu M}$ \\
\hline 1 & 10.9 \\
2 & 5.9 \\
3 & 4.7 \\
4 & 3.5 \\
\hline
\end{tabular}

$\mathrm{IC}_{50}$ values are the concentration corresponding to $50 \%$ inhibition of $\mathrm{NO}$ production.

To further investigate the anti-inflammatory effects of $\mathbf{2}$, we examined the effect of $\mathbf{2}$ on LPS-induced production of inflammatory mediators, including NO and Interleukin-6 (IL-6), in RAW 264.7 cells. As shown in Figure 9A,B, the treatment of RAW 264.7 cells with LPS increased the accumulation of nitrite and IL-6, and 2 dose-dependently inhibited LPS-induced production of nitrite and IL-6 in LPS-stimulated RAW 264.7 cells. To further investigate whether the effects of $\mathbf{2}$ were due to its effects on the mRNA expression of cognate genes, we examined the effect of $\mathbf{2}$ on the mRNA expression of inducible nitric oxide synthase (iNOS) and IL-6 by qPCR. The mRNA levels of iNOS and IL-6 were induced by LPS treatment, and this induction was suppressed by 2 in a dose-dependent manner (Figure 9D,E).

(A)

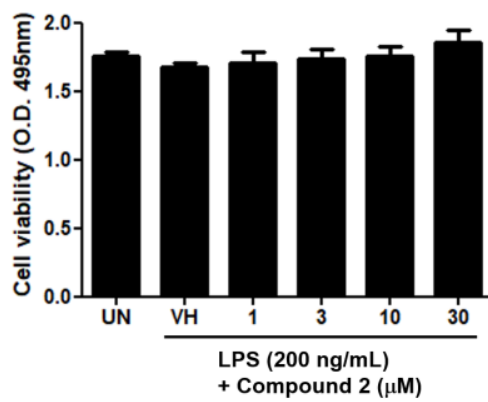

(D)

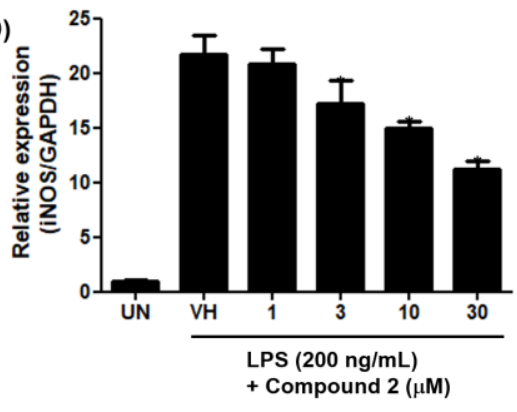

(B)

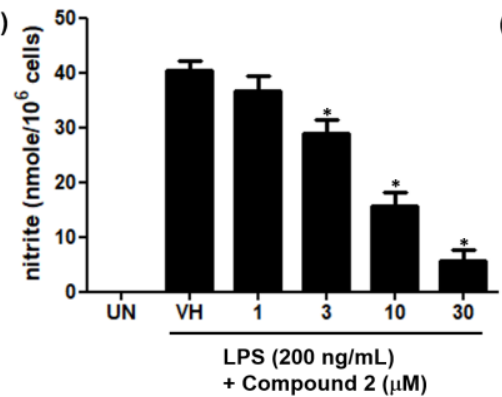

(E)

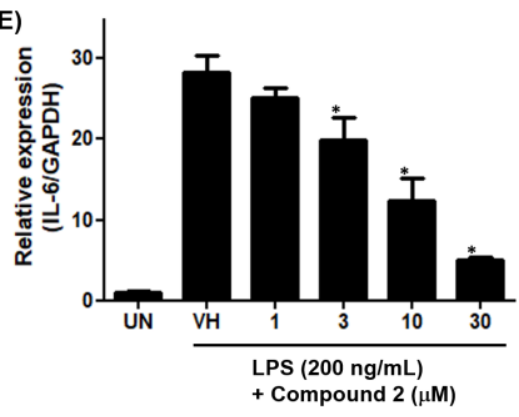

(C)

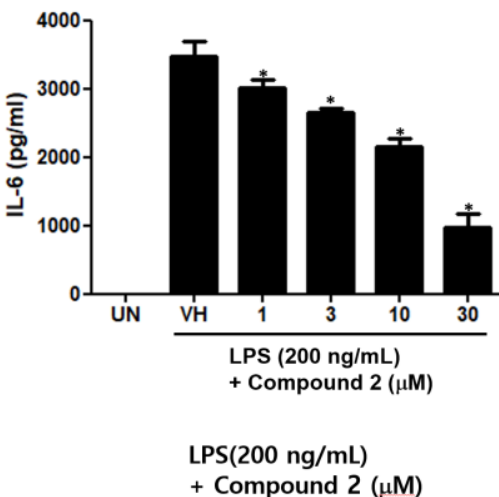

(F)

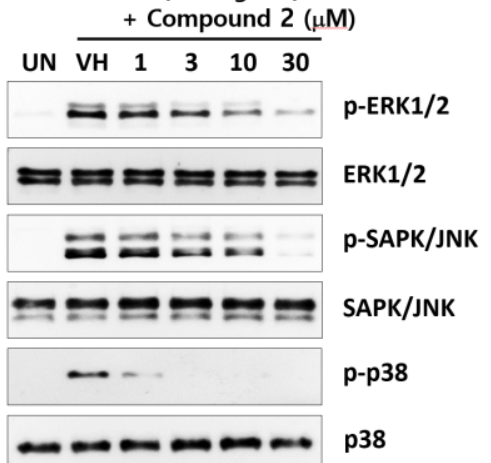

Figure 9. Inhibitory effects of 2 on LPS-induced nitrite production and IL-6 secretion in RAW 264.7 cells. RAW 264.7 cells were pretreated with the indicated concentrations of 2 for $1 \mathrm{~h}$ and stimulated with LPS (200 ng/mL) for $24 \mathrm{~h}$. (A) Cell viability was determined by XTT assay. The levels of nitrite (B) and IL-6 (C) in culture supernatants were determined by Griess reaction and ELISA, respectively. The mRNA levels of iNOS (D) and IL-6 (E) were examined by qPCR. Data are represented as mean \pm S.D. of quadruplicate determinations. ${ }^{*}$ denotes that the response is significantly different from vehicle-treated group as determined by Dunnett's multiple comparison test at $p<0.05$. (F) MAPK activation was tested by Western Immunoblot Analysis. The results shown are representatives of more than two independent experiments.

The concentrations of 2 used in this study had no cytotoxic effect on the viability of RAW 264.7 cells. Additionally, the mitogen-activated protein kinase (MAPK) activation 
study showed that phosphorylation of extracellular signal-regulated protein kinases (ERK), c-Jun N-terminal kinase (JNK) and p38 proteins was inhibited by $\mathbf{2}$ (Figure 9). The ERK, JNK and p38 proteins belonging to the MAPK superfamily are phosphorylated in the cytoplasm of stimulated cells by LPS. The activated p-ERK, p-JNK and p38 proteins activate transcription factors related with inflammation in their nucleus. Thus, $\mathbf{2}$ is considered to have anti-inflammatory activity by inhibiting the activation of the MAPK pathway.

\section{Materials and Methods}

\subsection{General Experimental Procedures}

The 1D and 2D NMR spectra were acquired on a Bruker $600 \mathrm{MHz}$ spectrometer (Bruker BioSpin $\mathrm{GmbH}$, Rheinstetten, Germany). UV-VIS spectra were acquired by a Shimadzu UV-1650PC spectrophotometer (Shimadzu Corporation, Kyoto, Japan). IR spectra were acquired on a JASCO FT/IR-4100 spectrophotometer (JASCO Corporation, Tokyo, Japan). Optical rotations were recorded on a Rudolph Research Analytical (Autopol III) polarimeter. High-resolution ESIMS experiments were performed on a hybrid ion-trap time-of-flight mass spectrometer (Shimadzu LC/MS-IT-TOF, Kyoto, Japan). HPLC was performed on a RI-101(Shodex). Semi-preparative HPLC was conducted using an ODS column (YMCPack-ODS-A, $250 \times 10 \mathrm{~mm}$ i.d, $5 \mu \mathrm{m})$.

\subsection{Isolation and Cultivation of the Strain 208DD-067}

The strain 208DD-067 was isolated from a sediment sample collected in Dokdo, South Korea in August 2020. The strain was identified as Streptomyces specialis on the basis of 16S rRNA gene sequence analysis (GenBank accession number OL691077). The seed and mass cultures of the strain 208DD-067 were performed in Bennett's medium (BN broth, 1\% glucose, $0.2 \%$ tryptone, $0.1 \%$ yeast extract, $0.1 \%$ beef extract, $0.5 \%$ glycerol, $3.2 \%$ sea salt, pH 7.0 before sterilization). A single colony of the strain from the agar plate was inoculated aseptically into a $2 \mathrm{~L}$ flask filled with $1 \mathrm{~L}$ of $\mathrm{BN}$ broth. After that, the strain was incubated at $24{ }^{\circ} \mathrm{C}$ for 7 days on a rotary shaker at $120 \mathrm{rpm}$ and then the culture broth was transferred to a $100 \mathrm{~L}$ fermenter filled with $70 \mathrm{~L}$ of BN broth. The mass culture was incubated for 21 days at $28{ }^{\circ} \mathrm{C}$ and then harvested.

\subsection{Extraction and Isolation of Metabolites}

The culture broth $(70 \mathrm{~L})$ was centrifuged $(60,000 \mathrm{rpm})$, and the supernatant was extracted twice with EtOAc $(70 \mathrm{~L})$. The EtOAc soluble part was evaporated to yield a crude extract $(7.0 \mathrm{~g})$. The extract was subjected to ODS open column chromatography followed by a stepwise gradient elution with $\mathrm{MeOH}$ in $\mathrm{H}_{2} \mathrm{O}(1: 4,2: 3,3: 2,4: 1$ and 100:0, v/v). The fraction eluted with $60 \% \mathrm{MeOH}$ in $\mathrm{H}_{2} \mathrm{O}$ was purified by a semi-preparative reversed-phase HPLC (YMC-Pack-ODS-A, $250 \times 10 \mathrm{~mm}$ i.d, $5 \mu \mathrm{m}$, flow rate $2.0 \mathrm{~mL} / \mathrm{min}$, RI detector) using an isocratic elution with $60 \% \mathrm{MeOH}$ in $\mathrm{H}_{2} \mathrm{O}$ to yield $\mathbf{1}\left(0.5 \mathrm{mg}, t_{\mathrm{R}}=36 \mathrm{~min}\right)$ and 2 $\left(0.9 \mathrm{mg}, t_{\mathrm{R}}=31 \mathrm{~min}\right)$ and the fraction eluted with $80 \% \mathrm{MeOH}$ in $\mathrm{H}_{2} \mathrm{O}$ was purified by a semi-preparative reversed-phase HPLC (YMC-Pack-ODS-A, $250 \times 10 \mathrm{~mm}$ i.d, $5 \mu \mathrm{m}$, flow rate $2.0 \mathrm{~mL} / \mathrm{min}$, $\mathrm{RI}$ detector) using an isocratic elution with $50 \% \mathrm{ACN}$ in $\mathrm{H}_{2} \mathrm{O}$ to yield 3 $\left(0.9 \mathrm{mg}, t_{\mathrm{R}}=20 \mathrm{~min}\right)$ and $4\left(1.2 \mathrm{mg}, t_{\mathrm{R}}=15 \mathrm{~min}\right)$.

Streptoglyceride E (1): a white powder; $[\alpha]_{\mathrm{D}}^{25}-20.0\left(\right.$ c 0.1, MeOH); IR $v_{\max } 3343,2960$, 2840, 1643, 1465, 1409, 1014 UV (MeOH) $\lambda_{\max }(\log \varepsilon) 202$ (3.45), 266 (2.48) nm; HRESIMS $\mathrm{m} / \mathrm{z} 301.1417[\mathrm{M}+\mathrm{Na}]^{+}$(calcd for $\left.\mathrm{C}_{16} \mathrm{H}_{22} \mathrm{O}_{4} \mathrm{Na}, 301.1416\right) ;{ }^{1} \mathrm{H}$ and ${ }^{13} \mathrm{C} \mathrm{NMR}$ data $\left(\mathrm{CD}_{3} \mathrm{OD}\right.$, $600 \mathrm{MHz}$ and $150 \mathrm{MHz}$, respectively), Table 1.

Streptoglyceride F (2): a white powder; $[\alpha]_{\mathrm{D}}^{25}+10.0$ (c 0.1, MeOH); IR $v_{\max } 3386,2921$, 2864, 2364, 2314, 1597, 1412, $1057 \mathrm{UV}(\mathrm{MeOH}) \lambda_{\max }(\log \varepsilon) 266$ (2.45) nm; HRESIMS m/z $301.1417[\mathrm{M}+\mathrm{Na}]^{+}$(calcd for $\left.\mathrm{C}_{16} \mathrm{H}_{22} \mathrm{O}_{4} \mathrm{Na}, 301.1416\right) ;{ }^{1} \mathrm{H}$ and ${ }^{13} \mathrm{C} \mathrm{NMR}$ data $\left(\mathrm{CD}_{3} \mathrm{OD}\right.$, $600 \mathrm{MHz}$ and $150 \mathrm{MHz}$, respectively), Table 1.

Streptoglyceride G (3): a white powder; $[\alpha]_{\mathrm{D}}^{25}-40.0$ (c 0.1, MeOH); IR $\nu_{\max } 3356,2967$, 2349, 2311, 1649, 1543, 1066 UV (MeOH) $\lambda_{\max }(\log \varepsilon) 231$ (2.45), 265 (2.48) nm; HRESIMS 
$m / z 315.1570[\mathrm{M}+\mathrm{Na}]^{+}$(calcd for $\left.\mathrm{C}_{17} \mathrm{H}_{24} \mathrm{O}_{4} \mathrm{Na}, 315.1572\right) ;{ }^{1} \mathrm{H}$ and ${ }^{13} \mathrm{C}$ NMR data $\left(\mathrm{CD}_{3} \mathrm{OD}\right.$, $600 \mathrm{MHz}$ and $150 \mathrm{MHz}$, respectively), Table 1.

Streptoglyceride H (4): a white powder; $[\alpha]_{\mathrm{D}}^{25}+30.0$ (c 0.1, MeOH); IR $v_{\max } 3392$, 2965, 2929, 2876, 1646, 1596, 1455, 1374, 1212, 1059 UV (MeOH) $\lambda_{\max }(\log \varepsilon) 266$ (2.45) nm; HRESIMS $m / z 315.1573[\mathrm{M}+\mathrm{Na}]^{+}$(calcd for $\mathrm{C}_{17} \mathrm{H}_{24} \mathrm{O}_{4} \mathrm{Na}, 315.1572$ ); ${ }^{1} \mathrm{H}$ and ${ }^{13} \mathrm{C}$ NMR data $\left(\mathrm{CD}_{3} \mathrm{OD}, 600 \mathrm{MHz}\right.$ and $150 \mathrm{MHz}$, respectively), Table 1 .

\subsection{Cell Viability Assay}

Cell viability assay was performed using a Cell Proliferation Kit II (Roche Applied Science, Mannheim, Germany) according to the manufacturer's instructions. Briefly, the XTT labeling mixture was prepared by mixing 50 volumes of $1 \mathrm{mg} / \mathrm{mL}$ sodium 3'-[1(phenylaminocarbonyl)-3,4-tetrazolium]-bis(4-methoxy-6-nitro)benzene sulfonic acid hydrate with 1 volume of $0.383 \mathrm{mg} / \mathrm{ml}$ of $\mathrm{N}$-methyldibenzopyrazine methyl sulfate, added to the cultures and incubated for $2 \mathrm{~h}$ at $37^{\circ} \mathrm{C}$. Absorbance was measured at $495 \mathrm{~nm}$ with a reference wavelength at $650 \mathrm{~nm}$.

\subsection{Computational Methods}

Conformational analysis was performed using molecular mechanics force-field (MMFF94s) calculations with a search limit of $3.0 \mathrm{kcal} \mathrm{mol}^{-1}$ in CONFLEX version 8.0 program (CONFLEX Corporation, Tokyo, Japan). The low-energy conformers were further optimized using the density functional theory (DFT) method at the B3LYP/6-311G+(d,p) level. The theoretical ECD spectra were calculated by Gaussian 16 software (Gaussian Inc., Wallingford, CT, USA) using the time-dependent density functional theory (TD-DFT) method at the B3LYP /6-311+G (d,p) level in MeOH with the Polarizable Continuum Model (PCM) utilizing the integral equation formalism variant (IEFPCM) model. The Boltzmann distributions of conformers were calculated based on their Hartrees energy, and the calculated ECD spectra were averaged according to the Boltzmann distributions. NMR chemical shifts were calculated by a gauge-independent atomic orbitals (GIAO) method at the B3LYP/6-311+G(d,P)/IEFPCM level in MeOH.

\subsection{Nitrite Quantification}

$\mathrm{NO}_{2}{ }^{-}$accumulation was used as an indicator of $\mathrm{NO}$ production in the medium. RAW 264.7 cells were plated at $5 \times 10^{5}$ cells $/ \mathrm{mL}$ and stimulated with LPS $(200 \mathrm{ng} / \mathrm{mL})$ in the presence or absence of $2(1,3,10$ or $30 \mu \mathrm{M})$ for $24 \mathrm{~h}$. The isolated supernatants were mixed with an equal volume of Griess reagent ( $1 \%$ sulfanilamide, $0.1 \%$ naphthylethylenediamine dihydrochloride, and $2 \%$ phosphoric acid), and incubated at room temperature for $10 \mathrm{~min}$. $\mathrm{NaNO}_{2}$ was used to generate a standard curve, and nitrite production was determined by measuring the optical density at $540 \mathrm{~nm}$.

\subsection{Enzyme-Linked Immunosorbent Assay (ELISA)}

RAW 264.7 cells were plated at $5 \times 10^{5}$ cells $/ \mathrm{mL}$ and stimulated with LPS $(200 \mathrm{ng} / \mathrm{mL})$ in the presence or absence of compound $2(1,3,10$ or $30 \mu \mathrm{M})$ for $24 \mathrm{~h}$. The culture supernatants were collected, and the amount of IL-6 was determined by mouse IL-6 ELISA kit (R\&D Systems, Minneapolis, MN, USA) according to the manufacturer's instructions.

\subsection{RNA Isolation and Quantification of mRNA Expression by $q P C R$}

Total cellular RNA was extracted using an RNeasy Plus Mini Kit (Qiagen, Valencia, CA, USA) with RNase-Free DNase Set (Qiagen) according to the manufacturer's instructions. cDNA was generated from total RNA by reverse transcription using AccuPower RT PreMix (Bioneer). The resulted cDNA was amplified by qPCR in conjunction with Power SYBR Green PCR Master Mix (Invitrogen, Carlsbad, CA, USA). For qPCR, samples were amplified by 45 cycles of denaturation $\left(95^{\circ} \mathrm{C}\right.$ for $\left.15 \mathrm{~s}\right)$ and amplification $\left(60^{\circ} \mathrm{C}\right.$ for $1 \mathrm{~min}$ using ABI 7500 Sequence Detection System (Applied Biosciences, Foster City, CA, USA). The gene expression levels relative to control gene (GAPDH) was calculated by $2^{-\Delta \Delta C t}$ method. 


\subsection{Western Immunoblot Analysis}

Twenty micrograms of whole-cell lysates were separated by $10 \%$ sodium dodecyl sulfate-polyacrylamide gel electrophoresis and electro-transferred to a nitrocellulose membrane (Amersham Biosciences UK, Ltd., Little Chalfont, Buckinghamshire, UK). Each membrane was pre-incubated for $1 \mathrm{~h}$ at room temperature in Tris-buffered saline, $\mathrm{pH}$ 7.6, containing $0.05 \%$ Tween 20 and 5\% nonfat milk. Each nitrocellulose membrane was incubated with specific antibodies against p-ERK1/2, ERK1/2, p-SAPK/JNK, SAPK/JNK, p-p38 and p38 (Cell Signaling Technology, Danvers, MA, USA). Immunoreactive bands were then detected by incubating with secondary IgG antibody conjugated with horseradish peroxidase and visualizing with enhanced chemiluminescence reagents (GE Healthcare, Chicago, IL, USA).

\subsection{Statistical Analysis}

One-way ANOVA followed by Dunnett's multiple comparison test was used for statistical analysis using GraphPad Prism (GraphPad Software, La Jolla, CA, USA). The criteria for statistical significance were set at ${ }^{*} p<0.05$.

\section{Conclusions}

We isolated four new streptoglycerides E-H (1-4) from a marine-derived actinomycete Streptomyces specialis. The structures of the new compounds (1-4) were elucidated by detailed analysis of HR-ESI-MS, 1D and 2D NMR data and ECD calculations. All compounds showed good anti-inflammatory activity with $\mathrm{IC}_{50}$ values ranging from 3.5 to $10.9 \mu \mathrm{M}$. Furthermore, the results demonstrated that 2 inhibited the mRNA expression of iNOS and IL-6 without cytotoxicity in RAW264.7 cells. According to this study, 2 inhibited the phosphorylation of ERK, JNK and p38 proteins in the MAPK pathway. To the best of our knowledge, this study represents the third example of marine natural products with a rare 6/5/5/-membered ring system and has anti-inflammatory activity. Streptoglycerides E-H (1-4) are a promising series of compounds with good anti-inflammatory activity and the potential for further therapeutic lead identification.

Supplementary Materials: The following are available online at https:/ /www.mdpi.com/article/10 .3390/md20010044/s1, Figures S1-S41: The analyzed data of MS, IR, 1D and 2D NMR spectra and Energy-minimized models of conformers of compounds 1-4, Table S1-S9: The calculated ECD data of compounds $\mathbf{1}-\mathbf{4}$.

Author Contributions: H.J.S. was the principal investigator, who proposed ideas for the present work, managed and supervised the whole research work, prepared and corrected the manuscript, and contributed to the structure elucidation of the new compounds. C.-S.H. conducted all experiments for compounds 1-4, including fermentation, isolation, and structure elucidation, and prepared the manuscript. C.V.A. contributed to analyzing data and visualization. J.S.K. and Y.D.Y. evaluated the anti-inflammatory activity of compounds 1-4. All authors have read and agreed to the published version of the manuscript.

Funding: This research was supported in part by the Korea Institute of Ocean Science and Technology (Grant PE99952) and the Ministry of Oceans and Fisheries, Republic of Korea (Grant PG52261).

Institutional Review Board Statement: Not applicable.

Data Availability Statement: The data presented in the article are available in the Supplementary Materials.

Acknowledgments: The authors express gratitude to Jung Hoon Choi, Korea Basic Science Institute, Ochang, Korea, for providing mass data.

Conflicts of Interest: The authors declare no conflict of interest. 


\section{References}

1. Herold, K.; Mrowka, R. Inflammation-Dysregulated inflammatory response and strategies for treatment. Acta Physiol. 2019, 226, e13284. [CrossRef] [PubMed]

2. Yoon, W.J.; Heo, S.J.; Han, S.C.; Lee, H.J.; Kang, G.J.; Kang, H.K.; Hyun, J.W.; Koh, Y.S.; Yoo, E.S. Anti-inflammatory effect of sargachromanol G isolated from Sargassum siliquastrum in RAW 264.7 cells. Arch. Pharmacal Res. 2012, 35, 1421-1430. [CrossRef]

3. Yang, S.H.; Le, B.; Androutsopoulos, V.P.; Tsukamoto, C.; Shin, T.-S.; Tsatsakis, A.M.; Chung, G. Anti-inflammatory effects of soyasapogenol I- $\alpha$ a via downregulation of the MAPK signaling pathway in LPS-induced RAW 264.7 macrophages. Food Chem. Toxicol. 2018, 113, 211-217. [CrossRef] [PubMed]

4. Turnquist, C.; Ryan, B.M.; Horikawa, I.; Harris, B.T.; Harris, C.C. Cytokine Storms in Cancer and COVID-19. Cancer Cell 2020, 38, 598-601. [CrossRef] [PubMed]

5. Sharma, J.N.; Al-Omran, A.; Parvathy, S.S. Role of nitric oxide in inflammatory diseases. Inflammopharmacology 2007, 15, 252-259. [CrossRef] [PubMed]

6. Tanaka, T.; Narazaki, M.; Kishimoto, T. IL-6 in inflammation, immunity, and disease. Cold Spring Harb. Perspect. Biol. 2014, 6 , a016295. [CrossRef] [PubMed]

7. Kobayashi, Y. The regulatory role of nitric oxide in proinflammatory cytokine expression during the induction and resolution of inflammation. J. Leukoc. Biol. 2010, 88, 1157-1162. [CrossRef] [PubMed]

8. Crisafulli, S.; Isgrò, V.; La Corte, L.; Atzeni, F.; Trifirò, G. Potential Role of Anti-interleukin (IL)-6 Drugs in the Treatment of COVID-19: Rationale, Clinical Evidence and Risks. BioDrugs Clin. Immunother. Biopharm. Gene Ther. 2020, 34, 415-422. [CrossRef] [PubMed]

9. Dang, H.T.; Lee, H.J.; Yoo, E.S.; Shinde, P.B.; Lee, Y.M.; Hong, J.; Kim, D.K.; Jung, J.H. Anti-inflammatory constituents of the red alga Gracilaria verrucosa and their synthetic analogues. J. Nat. Prod. 2008, 71, 232-240. [CrossRef] [PubMed]

10. Ha, T.M.; Kim, D.-C.; Sohn, J.H.; Yim, J.H.; Oh, H. Anti-Inflammatory and Protein Tyrosine Phosphatase 1B Inhibitory Metabolites from the Antarctic Marine-Derived Fungal Strain Penicillium glabrum SF-7123. Mar. Drugs 2020, 18, 247. [CrossRef] [PubMed]

11. Kim, Y.N.; Ji, Y.K.; Kim, N.-H.; Van Tu, N.; Rho, J.-R.; Jeong, E.J. Isoquinolinequinone Derivatives from a Marine Sponge (Haliclona sp.) Regulate Inflammation in In Vitro System of Intestine. Mar. Drugs 2021, 19, 90. [CrossRef] [PubMed]

12. Skropeta, D.; Wei, L. Recent advances in deep-sea natural products. Nat. Prod. Rep. 2014, 31, 999-1025. [CrossRef] [PubMed]

13. Jiménez, C. Marine Natural Products in Medicinal Chemistry. ACS Med. Chem. Lett. 2018, 9, 959-961. [CrossRef] [PubMed]

14. Manivasagan, P.; Venkatesan, J.; Sivakumar, K.; Kim, S.K. Pharmaceutically active secondary metabolites of marine actinobacteria. Microbiol. Res. 2014, 169, 262-278. [CrossRef] [PubMed]

15. Dharmaraj, S. Marine Streptomyces as a novel source of bioactive substances. World J. Microbiol. Biotechnol. 2010, 26, 2123-2139. [CrossRef]

16. Choi, B.-K.; Park, S.-Y.; Choi, D.-K.; Shin, B.; Shin, Y.-H.; Oh, D.-C.; Lee, H.-S.; Lee, H.-S.; Lee, Y.-J.; Lee, J.S.; et al. Streptoglycerides A-D with a Rare 6/5/5 Tricyclic Ring Skeleton from a Marine Actinomycete Streptomyces species. Org. Lett. 2018, 20, 6037-6040. [CrossRef]

17. Li, J.-Q.; Zhao, H.-W.; Ma, Z.-J. Cytotoxic bafilomycin analogues 6/5/5 with tricyclic ring system from a marine-derived Streptomyces sp. Tetrahedron Lett. 2020, 61, 151874. [CrossRef]

18. Xu, W.H.; Zhao, P.; Wang, M.; Liang, Q. Naturally occurring furofuran lignans: Structural diversity and biological activities Nat. Prod. Res. 2019, 33, 1357-1373. [CrossRef]

19. Jing, S.-S.; Wang, Y.; Yan, Y.-M.; Li, X.; Li, X.-J.; Zhao, C.-C.; Sun, J.-C.; Qiu, P.-Y.; Man, S.-L.; Gao, W.-Y. Diocollettines A, an unusual tricyclic diarylheptanoid derivative from the rhizomes of Dioscorea collettii. Tetrahedron Lett. 2016, 57, 3215-3217. [CrossRef]

20. Choi, B.-K.; Cho, D.-Y.; Choi, D.-K.; Shin, H.J. Miharadienes A-D with unique cyclic skeletons from a marine-derived Streptomyces miharaensis. Org. Chem. Front. 2021, 8, 4845-4852. [CrossRef] 